\title{
CONGENITAL SPIGELIAN HERNIA IN CHILDREN - CASE REPORT
}

\section{Florin Enache ${ }^{1}$, Constantin Tica $^{1}$}

\begin{abstract}
Spigelian hernia is an uncommon entity in children. The clinical signs can lead to a misdiagnose with inguinal hernias. In the literature there are only a few references to this kind of pathology. Usually these hernias associate cryptorchidism.

We report a 2-years-old boy with bilateral Spigelian hernia, bilateral undescended testis and hypospadias with penile curvature. The Spigelian hernias were repaired and bilateral orchidopexy was done after 3 months period. Hypospadias repair was done afterwards.
\end{abstract}

Keywords: Spiegel hernia, Abdominal wall defect, Congenital, Undescended testis, Children

\section{Introduction}

A Spigelian hernia is very rare and accounts for only $1.5 \%$ of the abdominal hernias in the population [1]. This condition is even rarer in childhood and can be often misdiagnosed with an inguinal hernia $[2,3]$, due to the different aspects in presentation, like size, location and symptoms [2-5].

Spiegel hernia is situated on the ventral side of the abdominal wall adjacent to the semilunar line. Adriaan van der Spiegel was the first to describe the semilunar line in 1645. But in 1764 Klinkosch [6] described a spontaneous lateral ventral hernia located in the semilunar line. The first who described this ventral hernia in a child was Scopinaro [7] in 1935.

Only about 70 cases were published until now in the literature [8]. In a review between 1935 and 2000 there have been only 37 cases reported in children [9]. These hernias are more frequent in males than females (ratio, $3.7: 1$ ), and they are more commonly on the left and may occur bilaterally in $15 \%$ of cases [10]. The majority of male patients associate cryptorchidism [11].

\section{Purpose}

Congenital Spigelian hernia are rarely seen in children. There are only few cases reported in the literature (about 35 cases) [1-3]. We report a male child with this rare condition managed successfully. He also had associated bilateral cryptorchidism and hypospadias with penile curvature.

\section{Material and method}

The case we want to present is a 2 years old male child with a bilateral Spigelian hernia, bilateral cryptorchidism, hypospadias and penile curvature. The case may be considered one with multiple pathologies which were treated sequentially with different types of surgical interventions.

\section{Results}

The child had a presentation in the pediatric surgical ambulatory department at the age of ten months were he was diagnosed with Spigelian hernia (fig. 1), bilateral cryptorchidism and hypospadias with penile curvature. After excessive crying and coughing, there were to bulges on the anterolateral abdominal wall.

The ultrasonogram showed a bilateral hernia sac that could be reduced by hand. Ultrasonography didn't have a major role in the diagnosis.

The child underwent surgery for the bilateral repair of anterior abdominal wall by open technique (figs. $2 \& 3$ ). The weakness found in the transversalis fascia was sutured bilaterally.

Then, after about three months a right orchidopexy was done and after another three months he underwent left orchidopexy. The spermatic cords were long enough to allow a normal testicular descent and lengthening was not required. The patent processes vaginalis was closed. The testis were hypertrophic, with abnormal epididymis and absence of the gubernaculum.

None of the two defects had recurrences and both testis were successfully present in the scrotum. The one stage intervention for hypospadias with urethroplasty and penile curvature repair was done at the age of two years with no complications.

In the literature the authors divide the Spigelian hernias in two categories based on site of origin of the sac: the ones with cryptorchidism the sac is originating from Spigelian fascia inferomedial to inferior epigastric vessels (low Spigelian hernias), the ones without cryptorchidism and female patients have hernia sac arising from the Spigelian belt superolateral to the inferior epigastric vessels (high Spigelian hernias) [12,13]. Brendan's hypothesis sustain that in low Spigelian hernia the testis has an ectopic location and is maldescended [14].

${ }^{1}$ Faculty of Medicine, Ovidius University of Constanța, Romania

E-mail: dr.enache@chirurgiecopii.ro, tica.constantin@yahoo.com 


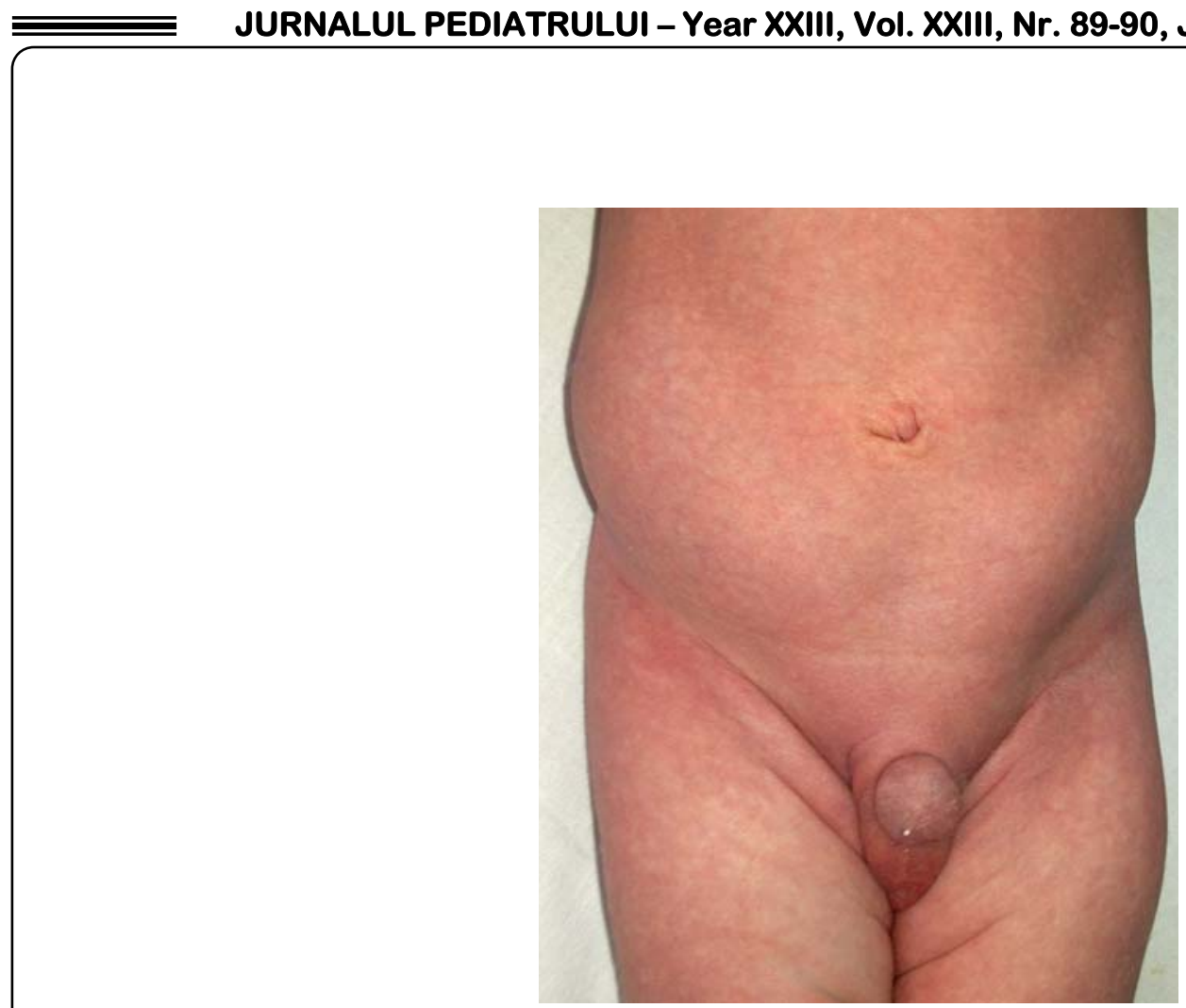

Fig. 1. Bilateral Spigelian hernia shows like two lumps in the anterolateral abdominal wall

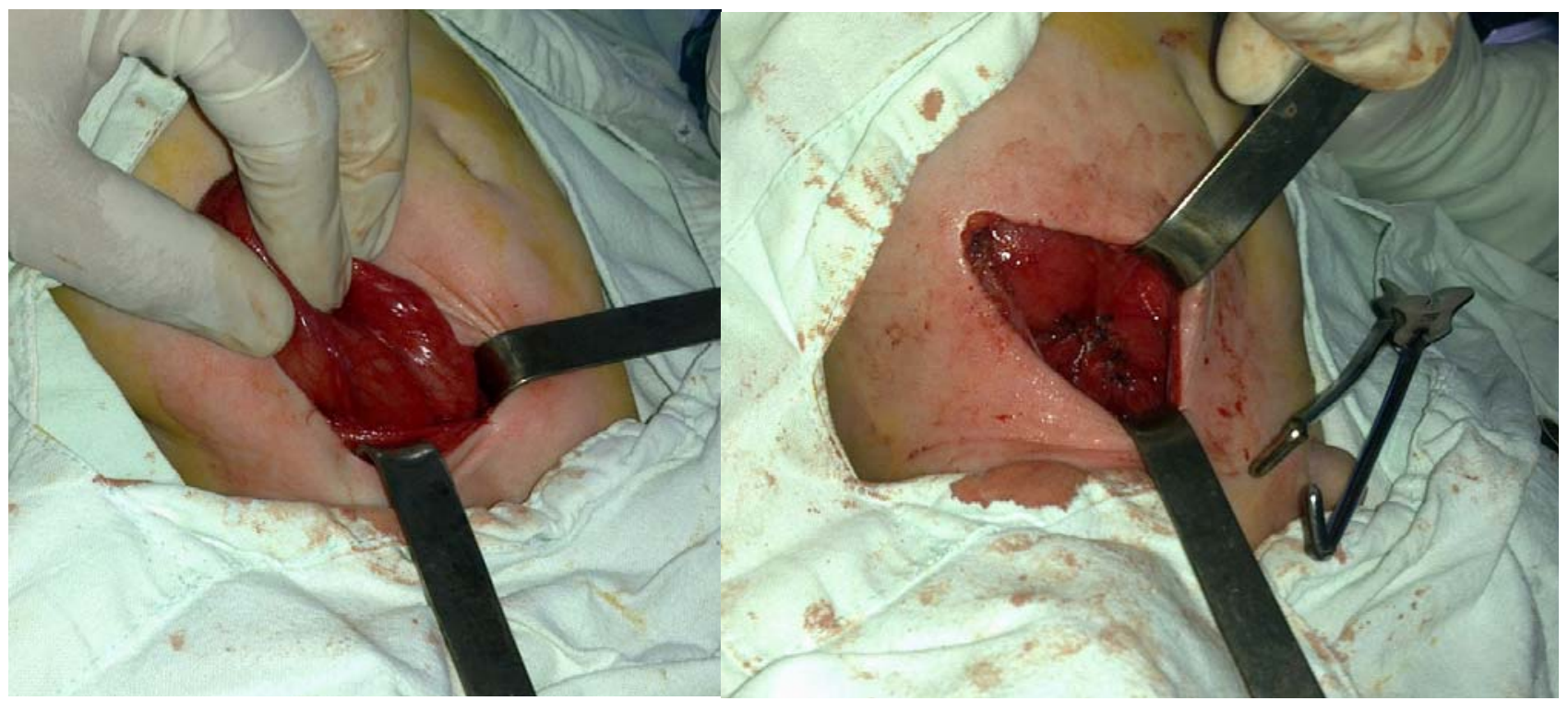

Fig. 2 \& 3. Spigelian hernia sac and suture of the weakness in the transversalis fascia 


\section{Conclusions}

Our case presented a high located weakness found in the transversalis fascia with a not well-defined sac, bilaterally, which was treated by hernioraphy. Concomitant the patient had cryptorchidism with a patent processes vaginalis treated successfully by bilateral orchidopexy, after a three months period.

\section{References}

1. Wu CM, Liu TH, Lin HJ, Wang GT. (2006) Traumatic Spigelian hernia.

2. Spinelli C, Strambi S, Pucci V, et al. Spigelian hernia in a 14 year-old girl: a case report and review of the literature. Eur J Pediatr Surg Rep 2014;2:58-62.

3. Bilici S, Cunes M, Goksu M, et al. Undescended testis accompanying congenital Spigelian hernia: is it a reason, a result, or a new syndrome? Eur J Pediatr Surg 2012;22:157-61.

4. Al-Salem AH. Congenital Spigelian hernia and cryptorchidism: cause or coincidence. Pediatr Surg Int 2000;16:433-6.

5. Malik KA, Chopra P. Spigelian hernia: a rarity. J Pak Med Assoc 2006;56:47-9.

6. Klinkosch JT. Programma Quo Divisionem Herniarum, Novumque Herniae Ventralis Specium Proponit. Berman. Rotterdam; 1764.

7. Scopinaro AJ. Hernia on spigels semilunar line in a newborn. Sem Med 1935;1:284-285.

8. Jones BC, Hudson JM. The syndrome of Spigelian hernia and cryptorchidism: a review of pediatric literature. J Pediatr Surg 2015;50:325-30.

9. Al-Salem AH. Congenital Spigelian hernia and cryptorchidism: cause or coincidence? Pediatr Surg Int 2000;16(5-6):433-436.

10. Rushfeldt C, Oltmanns G, Vonen B. Spigeliancryptorchidism syndrome: a case report and discussion of the basic elements in a possibly new congenital syndrome. Pediatr Surg Int 2010;26(9):939-942.

11. Durham MM, Ricketts RR. Congenital Spigelian hernias and cryptorchidism. J Pediatr Surg 2006;41:1814-1817.

12. Spangen L. Spigelian hernia. Surg Clin North Am 1984;64:351-66.

13. Sengar M, Mohta A, Neogi S, Gupta A, Viswanathan V. Spigelian hernia in children: low versus classical. Journal of Pediatric Surgery 53 (2018) 2346-2348.

Correspondence to:

Florin-Daniel Enache

B1. LT3, Sc. D, Ap. 46

900407 Constanța, Romania

Tel. +4 0723012140

Email: dr.enache@chirurgiecopii.ro 